\title{
A national cohort study of parental socioeconomic status and non-fatal suicidal behaviour-the mediating role of school performance
}

Beata Jablonska ${ }^{1 *}$, Frank Lindblad ${ }^{2,3}$, Viveca Östberg ${ }^{4}$, Lene Lindberg ${ }^{1}$, Finn Rasmussen ${ }^{5}$ and Anders Hjern ${ }^{4,6}$

\begin{abstract}
Background: A link between low parental socioeconomic status and mental health problems in offspring is well established in previous research. The mechanisms that explain this link are largely unknown. The present study investigated whether school performance was a mediating and/or moderating factor in the path between parental socioeconomic status and the risk of hospital admission for non-fatal suicidal behaviour.

Methods: A national cohort of 447929 children born during 1973-1977 was followed prospectively in the National Patient Discharge Register from the end of their ninth and final year of compulsory school until 2001. Multivariate Cox proportional hazards and linear regression analyses were performed to test whether the association between parental socioeconomic status and non-fatal suicidal behaviour was mediated or moderated by school performance.

Results: The results of a series of multiple regression analyses, adjusted for demographic variables, revealed that school performance was as an important mediator in the relationship between parental socioeconomic status and risk of non-fatal suicidal behaviour, accounting for $60 \%$ of the variance. The hypothesized moderation of parental socioeconomic status-non-fatal suicidal behaviour relationship by school performance was not supported.

Conclusions: School performance is an important mediator through which parental socioeconomic status translates into a risk for non-fatal suicidal behaviour. Prevention efforts aimed to reduce socioeconomic inequalities in non-fatal suicidal behaviour among young people will need to consider socioeconomic inequalities in school performance.
\end{abstract}

Keywords: Non-fatal suicidal behaviour, Socioeconomic status, School performance, Cohort studies

\section{Background}

It is well recognised, that children from families with low socioeconomic status (SES) suffer from poor health more often and are more likely to face a wide range of other adversities than their counterparts from families with high SES [1-3]. Early socioeconomic disadvantage may also have lasting health consequences throughout the course of their life [4-6]. Much less is known about the underlying processes through which childhood

\footnotetext{
* Correspondence: beata.jablonska@ki.se

'Division of Applied Public Health, Department of Public Health Sciences, Karolinska Institutet, Stockholm, Sweden

Full list of author information is available at the end of the article
}

socioeconomic disadvantage translates into poor health later in life.

It has been a consistent finding that success in the school system depends heavily on the parents' SES [7-10]. Children from households with low SES do worse at school and achieve lower levels of education as adults than comparisons [11,12]. Educational outcomes, in turn, are critical to stratification processes affecting future employment opportunities and earnings potential [13]. Such stratification processes have been shown to have a strong influence on health outcomes. Better employment opportunities, safer work environments, and increased income, allowing investments in health 
and reducing economic instability, also enhance health and well-being. These work characteristics are, in turn, associated with a higher social position that is a predictor of good health per se [14]. Education is also associated with better health literacy and healthier lifestyles [15]. The benefits of education and the opportunities it provides are not confined to physical health but extend to mental health as well. A mounting body of literature indicates that education plays a major role in promoting mental health and preventing mental illness [16].

Despite this evidence, little emphasis has been placed on educational achievements during the school years as a possible link between low SES in childhood and the increased risk of poor mental health later in life. Although the hypothesis that the effect of childhood SES on subsequent mental health operates through its effect on education has been tested [4,17-19] and confirmed $[18,19]$ in several studies, the research in this area has focused on the mediating role of adult educational attainment. The potentially cumulative effect of low parental SES and poor school performance also needs to be considered.

Suicidal behaviour among young people is one important mental health outcome where low parental SES, low intelligence (IQ) and poor school performance seem to increase risk [20-24]. In addition, findings indicate that rather than having a threshold effect, the risk of non-fatal suicidal behaviour (NFSB) in young people follows a socioeconomic and educational or IQ gradient $[21,22,25,26]$. Adolescence/young adulthood is a relatively healthy period, however the vulnerability to NFSB is most pronounced during this stage of life [27-29]. Moreover, NFSB rates among young people in Sweden have steadily increased over the past decade. In 2009, the rates of hospital admissions for NFSB in the 15-24 year-old group were 120 in every 100,000 men and 285 in every 100,000 women [29].

In conclusion, relatively limited attention has been given to the mechanisms that may bridge or modify the relationship between parental SES and mental health in young people. The aim of this register-based study is to investigate whether the association between childhood socioeconomic environment and NFSB in young people, an understudied age-group in this sense, is mediated or moderated by school performance.

\section{Results}

A total of 4798 individuals were hospitalised due to NFSB at least once during the study period. The majority $(81 \%)$ had been categorised as intentional and the remaining $19 \%$ as events of undetermined intent. The most frequent method of injury was poisoning-86\% of the cases categorised as 'intentional injury' and 69\% of the cases categorised as the 'event of undetermined intent' (Table 1).

Descriptive data on NFSB and grade point average in relation to demographic data are presented in Table 2. There was a gradient between parental SES, rates of hospitalisation and grade point average: the lower the parental SES the higher the rate of hospitalisation and the lower the grade point average. Men had lower grade point average and hospitalisation rate than women. Young people of mixed ethnicity had a lower grade point average and higher hospitalisation rate than young people with a Swedish and non-Swedish background. For the residency category, both grade point average and hospitalisation rate were quite similar between the groups.

Parental SES was associated with school performance [standardised beta coefficients ranged between -0.34 (children of unskilled workers had 0.34 units lower grade point average than children of higher-level nonmanuals) and -0.13 (children of unskilled workers had 0.13 units lower grade point average than children of higher-level non-manuals); all at $p<0.0001$ ], indicating that the condition required at the first step of mediation was fulfilled. The association between school performance and NFSB $(\mathrm{HR}=0.39,95 \% \mathrm{CI}=0.38-0.41)$ satisfied the requirements of the second step of mediation.

Table 1 Methods of non-fatal suicidal ehavior (NFSB) in intentional and undetermined cases

\begin{tabular}{|c|c|c|}
\hline & $\begin{array}{c}\text { Intentional NFSB } \\
\mathrm{N}(\%)\end{array}$ & $\begin{array}{l}\text { Event of undetermined intent } \\
\qquad \mathrm{N}(\%)\end{array}$ \\
\hline Poisoning & $3329(85.8)$ & $631(68.8)$ \\
\hline Poisoning by and exposure to alcohol & $64(1.6)$ & $16(1.7)$ \\
\hline Sharp object & $221(5.7)$ & $36(3.9)$ \\
\hline Hanging, strangulation, suffocation & $43(1.1)$ & - \\
\hline Jumping from high place & $57(1.5)$ & \\
\hline Smoke, fire, flames, steam, hot vapours & $16(0.4)$ & $101(11.1)$ \\
\hline Other/Unspecified means & $151(3.9)$ & $133(14.5)$ \\
\hline$\overline{\text { All }}$ & 3881 & 917 \\
\hline
\end{tabular}


Table 2 Number of cases and crude rates of hospital admission due to non-fatal suicidal behaviour (NFSB) and mean of grade point average by parental SES and demographic factors

\begin{tabular}{|c|c|c|c|c|c|}
\hline & \multirow{2}{*}{$\begin{array}{l}\text { Number of participants and distribution } \\
\qquad \mathrm{N}(\%)\end{array}$} & \multicolumn{3}{|c|}{$\begin{array}{l}\text { Number of cases and crude rates of } \\
\text { hospital admission due to NFSB }\end{array}$} & \multirow{2}{*}{$\begin{array}{c}\text { Grade point average } \\
\text { Mean (SD) }\end{array}$} \\
\hline & & $\begin{array}{c}\text { All } \\
\mathrm{N}(\%)\end{array}$ & $\begin{array}{l}\text { Women } \\
\mathrm{N}(\%)\end{array}$ & $\begin{array}{c}\text { Men } \\
\mathrm{N}(\%)\end{array}$ & \\
\hline \multicolumn{6}{|l|}{ Gender } \\
\hline Men & $230275(51.4)$ & $1649(0.7)$ & - & - & $3.11(0.68)$ \\
\hline Women & 217654 (48.6) & $3149(1.4)$ & - & - & $3.38(0.65)$ \\
\hline \multicolumn{6}{|l|}{ Parental SES } \\
\hline Higher level non-manuals & 86821 (19.4) & $661(0.8)$ & $426(1.0)$ & $235(0.5)$ & $3.58(0.61)$ \\
\hline Middle level non-manuals & $102967(23.0)$ & $922(0.9)$ & $631(1.3)$ & $291(0.5)$ & $3.37(0.62)$ \\
\hline Lower level non-manuals & $56814(12.7)$ & $570(1.0)$ & $361(1.3)$ & $209(0.7)$ & $3.20(0.64)$ \\
\hline Skilled workers & $72217(16.1)$ & $844(1.2)$ & $554(1.6)$ & $290(0.8)$ & $3.04(0.64)$ \\
\hline Unskilled workers & $63808(14.2)$ & $948(1.5)$ & $626(2.0)$ & $322(1.0)$ & $2.93(0.66)$ \\
\hline Other & 65302 (14.6) & $853(1.3)$ & $551(1.7)$ & $302(0.9)$ & $3.10(0.67)$ \\
\hline \multicolumn{6}{|l|}{ Ethnicity } \\
\hline Swedish & 391067 (87.3) & $3878(1.0)$ & $2534(1.3)$ & $1344(0.7)$ & $3.25(0.67)$ \\
\hline Non-Swedish & $25641(5.7)$ & $359(1.4)$ & $244(2.1)$ & $115(1.0)$ & $3.18(0.68)$ \\
\hline Mixed & $31221(7.0)$ & $561(1.8)$ & $377(2.5)$ & $184(1.2)$ & $3.19(0.70)$ \\
\hline \multicolumn{6}{|l|}{ Residency } \\
\hline Stockholm, Malmö, Gothenburg & $114833(25.6)$ & $1341(1.2)$ & $903(1.6)$ & $438(0.7)$ & $3.31(0.68)$ \\
\hline Other city & $233697(52.2)$ & $2463(1.1)$ & $1573(1.4)$ & $890(0.7)$ & $3.23(0.67)$ \\
\hline Rural & $99346(22.2)$ & $993(1.0)$ & $672(1.4)$ & $321(0.6)$ & $3.19(0.67)$ \\
\hline
\end{tabular}

Table 3 presents Cox regression models of the mediation analysis of parental SES, school performance and hospital admission due to NFSB. In model 1 (step 3 of mediation), adjusted for year of birth and gender, ethnicity and residency, the risk of NFSB increased with decreasing level of parental SES. Additional adjustment for grade point average in model 2 (step 4 of mediation) abolished this increased risk. These patterns were similar for both men and women. The results from the Sobel test confirmed that school performance significantly mediated the association between parental SES and the risk of NFSB $(z=-38.9, p<.0001)$, accounting for $60 \%$ of the explained variance.
When interaction terms were add to the Cox proportional hazard regression model, the strength of the inverse association between parental SES and risk of NFSB did not vary according to school performance (grade point average). No significant interactions were found between the level of parental SES and school performance with respect to the effect of these variables on risk of NFSB (Table 4).

\section{Discussion}

The main finding of this study is that the negative association between parental SES and NFSB during adolescence/young adulthood to a large extent was mediated

Table 3 Hazard ratios (95\% confidence intervals) for hospital admission due to non-fatal suicidal behaviour (NFSB) by parental SES

\begin{tabular}{|c|c|c|c|c|c|c|}
\hline & \multicolumn{2}{|l|}{ All } & \multicolumn{2}{|l|}{ Women } & \multicolumn{2}{|l|}{ Men } \\
\hline & $\begin{array}{l}\text { Model } 1 \\
(\mathrm{HR}, 95 \% \mathrm{Cl})\end{array}$ & $\begin{array}{l}\text { Model } 2 \\
(\mathrm{HR}, 95 \% \mathrm{Cl})\end{array}$ & $\begin{array}{l}\text { Model } 1 \\
(\mathrm{HR}, 95 \% \mathrm{Cl})\end{array}$ & $\begin{array}{l}\text { Model } 2 \\
(\mathrm{HR}, 95 \% \mathrm{Cl})\end{array}$ & $\begin{array}{l}\text { Model } 1 \\
(\mathrm{HR}, 95 \% \mathrm{Cl})\end{array}$ & $\begin{array}{l}\text { Model } 2 \\
(\mathrm{HR}, 95 \% \mathrm{Cl})\end{array}$ \\
\hline \multicolumn{7}{|l|}{ Parental SES } \\
\hline Higher level non-manuals & $1+$ & $1+$ & $1 \dagger$ & $1+$ & $1+$ & $1+$ \\
\hline Middle level non-manuals & $1.2(1.1-1.3)$ & $1.0(0.9-1.1)$ & $1.3(1.1-1.4)$ & $1.1(0.9-1.2)$ & $1.1(0.9-1.2)$ & $0.8(0.7-1.0)$ \\
\hline Lower level non-manuals & $1.3(1.2-1.5)$ & $0.9(0.8-1.0)$ & $1.3(1.1-1.5)$ & $0.9(0.8-1.1)$ & $1.4(1.1-1.7)$ & $0.9(0.8-1.1)$ \\
\hline Skilled workers & $1.5(1.4-1.7)$ & $0.9(0.9-1.1)$ & $1.6(1.4-1.8)$ & $1.0(0.9-1.1)$ & $1.5(1.3-1.8)$ & $0.9(0.7-1.0)$ \\
\hline Unskilled workers & $1.9(1.7-2.1)$ & $1.0(0.9-1.2)$ & $1.9(1.7-2.2)$ & $1.1(0.9-1.2)$ & $1.9(1.6-2.2)$ & $0.9(0.8-1.1)$ \\
\hline Other & $1.7(1.6-1.9)$ & $1.1(1.0-1.2)$ & $1.7(1.5-1.9)$ & $1.1(1.0-1.3)$ & $1.7(1.5-2.1)$ & $1.0(0.9-1.2)$ \\
\hline
\end{tabular}

Model 1 = adjusted for year of birth, gender, ethnicity, and residency. Model 2 = as model 1 with additional adjustment for mean of grade point average $\dagger=$ reference group 
Table 4 Hazard ratios (95\% confidence intervals) for hospital admission due to non-fatal suicidal behaviour NFSB by SES*Grade point average

\begin{tabular}{|c|c|c|c|}
\hline & $\begin{array}{l}\text { All } \\
(\mathrm{HR}, 95 \% \mathrm{Cl})\end{array}$ & $\begin{array}{l}\text { Women } \\
(\mathrm{HR}, 95 \% \mathrm{Cl})\end{array}$ & $\begin{array}{l}\text { Men } \\
\text { (HR, 95\% Cl) }\end{array}$ \\
\hline \multicolumn{4}{|l|}{ SES*Grade point average } \\
\hline Higher level non-manuals*Grade point average & $1 \dagger$ & $1+$ & $1 \dagger$ \\
\hline Middle level non-manuals*Grade point average & $1.0(0.9-1.2)$ & $1.0(0.8-1.2)$ & $0.9(0.7-1.2)$ \\
\hline Lower level non-manuals*Grade point average & $1.1(0.9-1.3)$ & $1.1(0.9-1.4)$ & $1.0(0.8-1.4)$ \\
\hline Skilled workers*Grade point average & $1.0(0.8-1.1)$ & $0.9(0.8-1.1)$ & $0.9(0.7-1.2)$ \\
\hline Unskilled workers*Grade point average & $1.1(0.9-1.3)$ & $1.1(0.9-1.3)$ & $1.0(0.8-1.3)$ \\
\hline Other*Grade point average & $0.9(0.8-1.1)$ & $0.8(0.7-1.0)$ & $1.1(0.9-1.4)$ \\
\hline
\end{tabular}

Adjusted for year of birth, gender, ethnicity, SES, residency and mean of grade point average

$\dagger=$ reference group

by school performance, accounting for as much as $60 \%$ of the variance. These findings are consistent with the large body of literature that has demonstrated the parallel links of parental SES to school performance $[11,12]$ and NFSB, respectively [21]. However, this is the first study to examine the mediating role of school performance. We found no evidence for the hypothesis that the vulnerability to NFSB as a function of family socioeconomic environment may be moderated by school performance. This indicates that, although children with low SES face greater risk of poor school performance and, due to this fact, are overrepresented among selfinjuring youth, the effect of poor school performance on the risk of NFSB seems to be equal for all SES-groups.

Parental SES had no effect on the risk of NFSB over and above what was mediated by school performance suggesting that childhood disadvantages act on a later risk of NFSB primarily in terms of the pathway effect. This means that low SES children tend to have a higher risk of NFSB and that risk can be understood in terms of them performing worse at school than comparisons. Thus, parental SES contributes to the intergenerational transmission of health disparities by placing children on different pathways leading to different mental health outcomes. The poor school performance of low SES children may be seen as a prolongation of the disadvantage experienced by one generation in the lives of the next and different mechanisms induced from conception onwards, by both material and non-material parental disadvantage, may be involved in impeding an underprivileged child's ability to reach his or her academic potential. For example, recent studies suggest that low SES increases the risk of exposure to adverse circumstances surrounding gestation and birth (e.g. inadequate nutrition, toxic exposure and stress) [30] that can negatively influence brain development $[31,32]$ and its cognitive function in several ways [33]. Low parental SES is likely to be accompanied by financial strain and psychosocial adversity related to poor parental health, alcohol misuse, and family disruption $[1,3]$.
These circumstances can undermine the amount and quality of stimulation that the child receives at home which is necessary for his/her optimal cognitive development [34]. Furthermore, it is more common for lowSES children to live in poor neighbourhoods and attend schools with high percentages of disadvantaged and low-achieving students [35]. These environmental characteristics have been shown to account for some of the risk of underperformance on an individual level, over and above the effect of individual SES and cognitive abilities [36].

Inter-generational disadvantage resulting in poor school performance and, in consequence in NFSB, can also arise as an effect of restricted access to human, social, and cultural resources that enhance educational outcomes. Parental education, which is correlated with SES [37], may play a particularly important role in this regard. Although low educated parents may value education as much as high educated parents, they often lack the ability to encourage their children to value education. Low-educated parents are less able to provide their children with qualified help with homework, early training in behaviours and skills (e.g. literacy) that are valued by schools, and to encourage them to achieve the expected outcomes [38-40]. As a result, low-SES children are less familiar with school culture, values and expectations and therefore less well equipped to achieve educational goals. Better-educated parents are also more informed regarding strategic educational choices and better equipped to communicate with teachers $[3,8,41]$. These characteristics allow the parent to closely monitor the child's performance and be proactive in preventing academic failure.

The differences in school performance between low and high-SES students may, to some extent, reflect inherited cognitive ability. There are, however, findings which indicate lower heritability of cognition among children from lower, rather than higher, SES backgrounds [42], thus assigning greater importance for their cognitive outcomes to environmental factors. 
School performance may be an important path because it is highly determinative of other exposures related to mental health. Early school performance is an important source for identity formation and the development of social roles [43], for how peers rate each other's worth in the school's social hierarchy [44], and clearly contributes to educational attainment and occupational opportunities later in life. By enhancing cognitive abilities such as critical thinking, and problem solving, school performance may also directly influence mental health. These are useful not only within the confines of the classroom but they also apply to situations outside the realm of the school and result in real-world benefits, including better health [45].

The presence of full statistical mediation suggests that school performance provides the key to understanding the mechanism through which long-term effects of parental SES on the risk of self-injury was transmitted and contributes to growing evidence that school performance may play a key role in the prediction of NFSB. It also extends previous findings by suggesting that school performance is not only an independent predictor of NFSB but also serves as a mediator between parental SES and self-injury. These results are in line with previous findings showing that a large proportion of the effect of childhood SES on adult health operates through its effect on education $[18,19]$. However, whereas previous studies focused on educational attainment in adulthood, the current work suggests that educational stratification of mental health may already be discerned in the early stages of education.

The direct importance of school performance indicates that a child's SES is not fully determinative of later mental health problems expressed as NFSB. Thus, our findings suggest that when adequately meeting the academic needs of disadvantaged children, the negative health pathway caused by socioeconomic disadvantage may be counterbalanced or redirected.

\section{Limitations}

The Hospital Discharge Register only includes NFSB cases admitted to in-patient care. It does not detect cases not seeking medical help after an act of NFSB or those who attended primary or specialized medical care, but were not admitted to in-patient care. Compared with a recent population-based health survey conducted in 2009 by the National Public Health Institute, the figures for NFSB are lower in the present study. In that survey, 8\% of women and $3 \%$ of men aged 19-29, reported that they had, at least once, tried to take their own life [46]. It cannot be taken for granted that the role of socioeconomic inequality in school grades is similar in cases of NFSB not reported to the medical system or in less-severe cases not in need of in-patient care.
The register-based design of this study did not allow for the control of mental health conditions that do not lead to inpatient care. Thus, the reverse association, meaning that poor school performance may be a consequence of mental health problems, cannot be entirely excluded.

\section{Conclusions}

This study demonstrated that a substantial part of the association between parental SES and NFSB could be ascribed to the intermediate effect of school performance. This suggests that school interventions adequately meeting the academic needs of children from low socioeconomic background may have the potential to counterbalance the negative health effects caused by socioeconomic disadvantage. Educational strategies directed toward low-SES students' academic outcomes should be accompanied by the social ones that aim to reduce socioeconomic differences in psychosocial and environmental factors implicated in the academic success. The potential role of school performance as a pathway between parental SES and other health outcomes should be investigated further in future studies.

The evidence from the present study also suggests that the effect of poor school performance on the risk of NFSB seems to be equal for all SES-groups. Thus, to strengthen prevention strategies relating to mental health, investment in educational support for students failing to meet their potential is needed in all socioeconomic groups. Whether the mechanisms linking poor school performance and the risk of mental health problems are distinct for different SES groups is worthy of further investigation.

\section{Methods}

This study was based on data from national registers held by the Swedish National Board of Health and Welfare and Statistics Sweden. The key to these registers is the unique personal identification number. This number was used to link data from the registers to each person. The study was approved by the regional ethical review board at Karolinska Institutet, Stockholm, Sweden.

\section{Study population}

The study population consisted of the entire Swedish population born between 1973 and $1977(\mathrm{~N}=491$ 258), registered as residents in the Swedish Population and Housing Census of 1985 and with reports in the first five birth cohorts in the National School Register (see below). Individuals who had been admitted to a hospital due to a psychiatric disorder and/or NFSB before finishing ninth grade $(n=1670)$ were excluded. On the scale ranging from a minimum of 1.0 to a maximum of 5.0, their grade point average was 2.84 (standard deviation 
$(\mathrm{SD})=0.68)$ which was similar to those who had been admitted to a hospital after compulsory school, 2.87 (SD $=0.73$ ). Individuals who had three or more incomplete courses, i.e. courses that had not been formally graded by the end of the examination period due to an insufficient basis to evaluate student performance, $(n=7062)$ were also excluded because of their unreliable grade point average, as were foreign-born children ( $\mathrm{n}=$ 34,597 ) because of the negative influence of migration on school performance [47]. In total, 447929 persons comprised the study population.

\section{Outcome variable}

The outcome variable-first-time hospital admission due to "purposely self-inflicted poisoning or injury/suicide (attempted)" (ICD-10)-was obtained through individual record linkage to the National Hospital Discharge Register from 1987 to 2001. Hospital admission involves staying at a hospital for at least one night. NFSB was defined according to the ninth revision of the World Health Organization (WHO) International Classification of Diseases (ICD-9) (intentional self-harm E950-959 and event of undetermined intent E980-989) during 19871996 and the tenth revision (ICD-10) (intentional selfharm X60-84 and event of undetermined intent Y10-34) during 1997-2001.

\section{School performance}

Data on grade point averages at the time of leaving compulsory school (usually at 16 years of age) was collected from the National School Register. This register encompasses data from all public schools since 1988 and also data from all non-public schools, (less than 5\% of all Swedish schools) since 1993. Until 1996 a fivegraded relative scale was used in the Swedish school system, supervised by the Swedish School Authority through national tests in core subjects. The quality of the data in the National School Register is high and summary statistics are published regularly http://www. skolverket.se. Grade point average was calculated on the basis of the 17 school subjects and ranged from a minimum of 1.0 to a maximum of 5.0 , mean $=3.2, \mathrm{SD}=0.7$.

\section{Parental socioeconomic status}

The socioeconomic status of the household was obtained from the Swedish Population and Housing Census of 1985. SES was defined according to the classification used by Statistics Sweden which is based on occupation and also takes the occupation's level of qualification, type of production and position of work of the head of the household into account. Six categories of SES were created: unskilled workers, skilled workers, lower-level non-manuals, middle-level non-manuals, higher-level non-manuals, and others (i.e. the self- employed, farmers, students, housewives, old age/sickness disability pensioners, long-term unemployed). The highly heterogeneous composition of the SES category "other" was due to the relatively small numbers of individuals belonging to each subcategory.

\section{Demographic variables}

Demographic indicators were created through linkage to the Swedish Population and Housing Census of 1985: year of birth, gender, ethnicity, and geographical location of the home (residency). These variables have been selected because of their association to parental SES, school performance and NFSB in previous studies [21]. Information about parental country of birth was used to create a three-category proxy for ethnicity: Swedish (both parents born in Sweden), non-Swedish (neither parent born in Sweden), and mixed (one parent born in Sweden and one parent born in another country).

\section{Statistical methods}

Multivariate analyses were performed by Cox proportional hazards regression of time to first hospital admission due to NFSB as the outcome variable. Time in the study was calculated with the entry date defined as the date of graduation and the exit date as the date of the first hospital admission, date of death from the National Cause of Death Register, date of emigration from the Register of the Total Population or the end of follow-up (December 2001).

The mediating and moderating role of school performance in the association between parental SES and NFSB was tested according to the recommendations of Baron and Kenny (1986) [48]. The criteria required for mediation to occur were as follows: 1) parental SES predicts school performance; 2) school performance predicts NFSB; 3) parental SES predicts NFSB; 4) the relationship between parental SES and NFSB is attenuated to non-significance but not absolute zero (in the case of partial mediation) or abolished (in the case of total mediation), when controlling for school performance. Linear regression with dummy variables was used to test whether the first criterion was satisfied and Cox proportional hazards regressions were used to verify satisfaction of all other criteria. Additionally, the Sobel test was used to assess the statistical reliability of the degree of mediation $[48,49]$. The amount of explained variance accounted for by the mediation was also calculated.

The interaction term between parental SES and grade point average was formed by multiplying dummy coded parental SES by grade point average. Cox proportional hazards regression was performed using parental SES, grade point average and the interaction term between parental SES and grade point average. To reduce 
potential problems with multicollinearity between the interaction term with its component variables in the analysis of moderating effect, school performance was mean-centered by subtracting its sample mean from all individuals' values, thus producing a revised sample mean of zero [50].

All models were simultaneously adjusted for potential confounding factors (year of birth, gender, ethnicity, and residency). Year of birth was entered as a continuous variable into the regression models in accordance with the linear relation of this variable to the outcome. Other socio-demographic variables were entered as categorical variables into the models, and when necessary with the use of dummy variables. The SPSS software package, version 17.0 was used in all statistical analyses.

\section{Acknowledgements}

This work was supported by The Swedish Council for Working Life and Social Research [grant numbers: 2006-0197 and 2007-0834], The Clas Groschinsky Foundation and The Sven Jerring Foundation.

\section{Author details}

'Division of Applied Public Health, Department of Public Health Sciences, Karolinska Institutet, Stockholm, Sweden. ${ }^{2}$ Department of Neuroscience, Child and Adolescent Psychiatry, Uppsala University, Uppsala, Sweden. ${ }^{3}$ Stress Research Institute, Stockholm University, Stockholm, Sweden. ${ }^{4}$ Centre for Health Equity Studies (CHESS), Stockholm University/Karolinska Institutet, Stockholm, Sweden. ${ }^{5} \mathrm{Child}$ and Adolescent Public Health Epidemiology Group, Department of Public Health Sciences, Karolinska Institutet, Stockholm, Sweden. 'Department of Children's and Women's health, Uppsala University, Uppsala, Sweden.

\section{Authors' contributions}

$\mathrm{BJ}, \mathrm{FL}, \mathrm{AH}$ conceived of the study, participated in its design and drafted the manuscript. FR, AH participated in the acquisition of data. BJ performed the statistical analysis and participated in interpretation of data. VÖ helped to draft the manuscript. FL, VÖ, LL, FR, AH contributed to interpretation of the results and revision of the manuscript. All authors read and approved the final manuscript.

\section{Competing interests}

The authors declare that they have no competing interests.

Received: 4 October 2011 Accepted: 9 January 2012

Published: 9 January 2012

\section{References}

1. Halldorsson M, Kunst AE, Köhler L, Mackenbach JP: Socioeconomic inequalities in the health of children and adolescents. A comparative study of the five Nordic countries. Eur J Public Health 2001, 10:281-288.

2. McMunn AM, Nazroo JY, Marmot MG, Boreham R, Goodman R: Children's emotional and behavioural well-being and the family environment: findings from the Health Survey for England. Soc Sci Med 2001, 53:423-440.

3. Power $C$, Matthews S: Origins of health inequalities in a national population sample. Lancet 1997, 350:1584-1589.

4. Huurre T, Aro H, Rahkonen O: Well-being and health behaviour by parental socioeconomic status: a follow-up study of adolescents aged 16 until age 32 years. Soc Psychiatry Psychiatr Epidemiol 2003, 38:249-255.

5. Weitoft GR, Hjern A, Haglund B, Rosen M: Mortality, severe morbidity, and injury in children living with single parents in Sweden: a populationbased study. Lancet 2003, 361:289-295.

6. Power C, Stansfeld SA, Matthews S, Manor O, Hope S: Childhood and adulthood risk factors for socio-economic differentials in psychological distress: evidence from the 1958 British birth cohort. Soc Sci Med 2002, 55:1989-2004.

7. Erikson R, Jonson J: Can Education be Equalized. The Swedish Case in Comparative Perspective New York: Westview Press; 1996.

8. Jonsson JO: Utbildning som resurs under skoltiden och för framtiden: uppväxtfamilj och skolgång (Education as a resource in schooling and for the future: family and schooling). In Barn och ungdomars välfärd. Edited by: Jansson S, Östberg V. SOU 2001:59. Stockholm: Fritzes; 2001:209-238.

9. Gutman L, Sameroff A, Cole R: Academic growth curve trajectories from 1st grade to 12th grade: effects of multiple social risk factors and preschool child factors. Dev Psychol 2003, 39:777-790.

10. Sirin SR: Socioeconomic status and academic achievement: a metaanalytic review of research. Rev Educ Res 2005, 75:417-453.

11. Bradley RH, Corwyn RF: Socioeconomic status and child development. Annu Rev Psychol 2002, 53:371-399.

12. Lee V, Burkam D: Inequality at the Starting Gate: Social Background Differences in Achievement as Children Begin School Washington: Economic Policy Institute; 2002.

13. Currie J, Duncan T: Early test scores, school quality and SES: long run effects on wage and employment outcomes. Res Labor E 2001, 20:103-132.

14. Marmot M: The Status Syndrome New York: Henry Holt; 2004.

15. Wardle J, Steptoe A: Socioeconomic differences in attitudes and beliefs about healthy lifestyles. J Epidemiol Community Health 2003, 57:440-443.

16. Dalgard OS, Mykletun A, Rognerud M, Johansen R, Zahl PH: Education, sense of mastery and mental health: results from a nationwide health monitoring study in Norway. BMC Psychiatry 2007, 7:20.

17. Kestilä L, Koskinen S, Martelin T, Rahkonen O, Pensola T, Aro H, Aromaa A: Determinants of health in early adulthood: what is the role of parental education, childhood adversities and own education? Eur J Public Health 2006, 16:306-315.

18. Der G, Batty GD, Deary IJ: The association between IQ in adolescence and a range of health outcomes at 40 in the 19979 US National Longitudinal Study of Youth. Intelligence 2009, 3:573-580.

19. McKenzie SK, Carter K, Blakely T, Collings S: The association of childhood socioeconomic position and psychological distress in adulthood: is it mediated by adult socioeconomic position? Longit Life Course Stud 2010, 1:339-358

20. Fergusson DM, Woodward LJ, Horwod LJ: Risk factors and life processes associated with the onset of suicidal behaviour during adolescence and early adulthood. Psychol Med 2000, 30:23-39.

21. Jablonska B, Lindberg L, Lindblad F, Rasmussen F, Östberg V, Hjern A School performance and hospital admissions due to self-inflicted injury: a Swedish national cohort study. Int J Epidemiol 2009, 38:1334-1341.

22. Björkenstam C, Weitoft GR, Hjern A, Nordström P, Hallqvist J, Ljung R: School grades, parental education and suicide-a national register-based cohort study. J Epidemiol Community Health 2011, 65:993-998.

23. Andersson L, Allebeck P, Gustafsson JE, et al: Association of IQ scores and school achievement with suicide in a 40-year follow-up of a Swedish cohort. Acta Psychiatr Scand 2008, 118:99e105.

24. Gunnell D, Löfving S, Gustaffson JE, Allebeck P: School performance and risk of suicide in early adulthood: follow-up of two national cohorts of Swedish schoolchildren. J Affect Disord 2011, 131:104-112.

25. Lyons RA, Jones SJ, Deacon T, Heaven M: Socioeconomic variation in injury in children and older people: a population based study. Inj Prev 2003, 9:33-37.

26. Batty GD, Whitley E, Deary IJ, Gale CR, Tynelius P, Rasmussen F: Psychosis alters association between IQ and future risk of attempted suicide: cohort study of 1, 109, 475 Swedish men. BMJ 2010, 340:c2506.

27. Schmidtke A, Bille-Brache U, DeLeo D, et al: Attempted suicide in Europe: rates, trends and sociodemographic characteristics of suicide attempters during the period 1989-1992. Results of the WHO/EURO Multicentre Study on Parasuicide. Acta Psychiatr Scand 1996, 93:327-338.

28. Nock MK, Borges G, Bromet EJ, Cha CB, Kessler RC, Sing Lee S: Suicide and suicidal behavior. Epidemiol Rev 2008, 30:133-154.

29. The National Board of Health and Welfare: Skador och förgiftningar behandlade i sluten vård. Hospitalisation due to injuries and poisoning in Sweden 20092010 [http://www.socialstyrelsen.se]. 
30. Dawson G, Ashman SB, Carver LJ: The role of early experience in shaping behavioral and brain development and its implications for social policy. Dev Psychopathol 2000, 12:695-712.

31. Hackman DA, Farah MJ: Socioeconomic status and the developing brain. Trends Cogn Sci 2009, 13:65-73.

32. Tomalski $\mathrm{P}$, Johnson $\mathrm{H}$ : The effects of early adversity on the adult and developing brain. Curr Opin Psychiatry 2010, 23:233-238.

33. Hack M, Breslau N, Weissman B, Aram D, Klein N, Borawski E: Effect of very low birth weight and subnormal head size on cognitive abilities at school age. N Engl J Med 1991, 325:231-237.

34. Stein A, Malmberg L-E, Sylva K, Barnes J, Leach P, the FCCC team: The influence of maternal depression, caregiving, and socioeconomic status in the post-natal year on children's language development. Child Care Health Dev 2008, 34:603-612.

35. Statistics Sweden: Barn, boendesegregation och skolresultat. Children, segregated housing and school results Demografiska Rapporter (Demographic reports); 2007, 2.

36. Gutman LM, Feinstein L: Children's Well-Being in Primary School: Pupil and School Effects London: Centre for Research on the Wider Benefits of Learning Institute of Education; 2008.

37. Statistics Sweden: Utbildningsnivå efter indikator, socioekonomisk grupp och kön. Level of education by the indicator, socioeconomic group and gender [http://www.ssd.scb.se].

38. Guo G, Harris KM: The mechanisms mediating the effects of poverty on children's intellectual development. Demography 2000, 37:431-447.

39. De Civita M, Pagani L, Vitaro F, Tremblay RE: The role of maternal educational aspirations in mediating the risk of income source on academic failure in children from persistently poor families. Child Youth Serv Rev 2004, 26:749-769.

40. Werfhorst HG, Hofstede S: Cultural capital or relative risk aversion? Two mechanisms for educational inequality compared. Br J Sociol 2007, 58:391-415.

41. Due P, Lynch J, Holstein B, Modvig J: Socioeconomic health inequalities among a nationally representative sample of Danish adolescents: the role of different types of social relations. J Epidemiol Community Health 2003, 57:692-698.

42. Turkheimer E, Haley A, Waldron M, D'Onofrio B, Gottesman II: Socioeconomic status modifies heritability of IQ in young children. Psychol Sci 2003, 14:623-628.

43. Modin B, Ostberg V, Almquist $Y$ : Childhood peer status and adult susceptibility to anxiety and depression. A 30-year hospital follow-up. J Abnorm Child Psychol 2010, 39:187-199.

44. Baumeister RF, Campbell JD, Krueger JI, Vohs KD: Does high self-esteem cause better performance, interpersonal success, happiness, or healthier lifestyles? Psychol Sci Public Interest 2003, 4:1-44.

45. Reynolds JR, Ross CE: Social stratification and health: education's benefit beyond economic status and social origins. Soc Probl 1998, 45:221-247.

46. Clevenpalm J, Karlsson A-S: Health On Equal Terms? Results from the 2006 Swedish National Public Health Survey Public Health: Swedish National Institute of; 2009.

47. The Swedish National Agency for Education: Vad påverkar resultaten i svensk grundskola? Kunskapsöversikt om betydelsen av olika faktorer. Which factors affect the results of Swedish comprehensive school? An overview of the importance of different factors Stockholm: Fritzes; 2009.

48. Baron RM, Kenny DA: The moderator-mediator variable distinction in social psychological research: conceptual, strategic, and statistical considerations. J Pers Soc Psychol 1986, 51:1173-1182.

49. Herr NR: Mediation with dichotomous outcomes [http://nrherr.bol.ucla.edu/ Mediation/logmed.html].

50. Aiken LS, West SG: Multiple Regression: Testing and Interpreting Interactions Newbury Park: Sage; 1991.

\section{Pre-publication history}

The pre-publication history for this paper can be accessed here: http://www.biomedcentral.com/1471-2458/12/17/prepub

doi:10.1186/1471-2458-12-17

Cite this article as: Jablonska et al:: A national cohort study of parental socioeconomic status and non-fatal suicidal behaviour-the mediating role of school performance. BMC Public Health 2012 12:17. 